\title{
The College Aesthetic Education Teaching and Students' Psychological Mechanism Development in Network Age
}

\author{
Bianling Zhang \\ School of Art Design \\ Huanghe Science and Technology College \\ Zhengzhou, China \\ e-mail: 24196102@qq.com
}

\begin{abstract}
With the advent of the information age, the network teaching resources become very abundant. In this case, educators should actively create conditions, analyze psychological characteristics of students reasonably, and adjust the teaching ideas of their own in order to fit in with the needs of the times. Aesthetic education is to cultivate media literacy which refers to the abilities of accessing, understanding, questioning, evaluating, creating, production and speculative reaction for the processing of all kinds of media information. The cultivation of such abilities requires reforms and strengthening of aesthetic education. Colleges and universities should certainly take the corresponding responsibility of being the disseminator for aesthetic education, conduct in-depth study of the aesthetic education law in higher education and guide practice with scientific education theory.
\end{abstract}

Keywords-network era; colleges and universities; students, psychological mechanism; aesthetic education

\section{INTRODUCTION}

With the advent of the information age, network culture has become an inseparable part of modern people's daily life and learning. The discussion on the integration of aesthetic education into the whole process of school education is undertaken under the background that humans have entered the new century and the network era. Therefore, the study of the new opportunities and challenges brought by network culture for education is unavoidable. As educators, we should update the view. We should not only re-study of the purpose of aesthetic from the perspective of traditional teaching mode, but also specifically study and improve the teaching skills in order to develop and improve the teaching of aesthetic education more effectively in combination with the characteristics of the psychological mechanism of modern college students and the orientation of education in new period.

Aesthetic education is a powerful enhancement of people's specific value orientation, that is to say, the aesthetic education can guide people's value orientation and enable them to be good at realizing and evaluating beauty. Art Education in college is the main content of aesthetic education. The art cultivation of college students would enable them to grasp human aesthetic experience and get infection of beauty, improving aesthetic quality so as to achieve the all-round harmonious development physically and spiritually [1]. Aesthetic education has some other important functions. It could cultivate people's sentiments, make people become nobler, live a life conscientiously in accordance with the laws of beauty, which makes the world people live in more colorful, brilliant and beautiful. Besides, it makes the human civilization develop better.

\section{THE CHARACTERISTICS OF COLLEGE STUDENTS' PSYCHOLOGICAL MECHANISM ARE THE BASIS OF AESTHETIC EDUCATION RESEARCH}

As the leading aesthetic group of the era, college students have their own distinctive individuality and aesthetic values, starting aesthetic life style which is appropriate for the requirements of future social life. College students should learn knowledge from books and society as well. The starting point of the research requires us to have a scientific knowledge of students' psychological mechanism so as to do a better job of college aesthetic education in the new network era.

\section{A. College students' psychological mechanism is of characteristics of times in new era.}

The more novel the thing is, the more likely they would be attracted. This reflects that the psychological mechanism of college students have distinctive characteristics of the times. At university stage, students' intelligence develops significantly and their cognitive ability is greatly enhanced. They are no longer satisfied with the knowledge system from traditional teaching. They have strong self-consciousness, dare to challenge the authority. They are able to look at the individual, the life and the world with their own unique insight and perspective, making aesthetic choices with independent thinking. They like challenging and arguing, developing their own unique insights. In the new times the massive information resources and rapid transmission have strong impacts on aesthetic education. In order to adapt to this trend, we should strengthen the integration of aesthetic education and other courses. 


\section{B. The differences of college students' psychological mechanism}

Each individual's psychological mechanism varies since every college student has different experience. Different students differ in the aspects of interest, emotion, personality and will-power. Since information resources accepted by the same student in different stages are different, the individual temperament also varies. The characteristics of students' psychological mechanism provide a scientific basis for the application of the new teaching methods of aesthetic education. Like many other disciplines, aesthetic education is changing significantly in the aspects of the method, approach and concept as well. The lack of aesthetic education in Chinese traditional culture is getting more and more obvious, which is undoubtedly indicating a new direction of Chinese aesthetic education, worthy of exploration and research. The aesthetic demand by undergraduate students is especially urgent and this phenomenon attains more attention and study by art educators gradually. As educators, we should actively discuss, study, practice and explore one way out which is appropriate for modern aesthetic education of students.

\section{The diversified integration between aesthetic education and students' psychological mechanism}

Education determines what media and technology to use and how to utilize them. However, media and technology in turn also affect the education and change the education [2]. At the same time that educators conduct aesthetic education via teaching methods and approaches, effects of pedagogy should also be emphasized. During University, the development of students' temperament is of strong feasibility. At this stage the teaching of network aesthetic education in class caters to the strong desire for knowledge and curiosity of network information by contemporary college students in time. The teacher is an important factor for promoting the aesthetic education. A qualified teacher with modern consciousness should actively create conditions, reasonably analyze psychological characteristics of students and utilize network information technology to arrange teaching contents scientifically. Teachers should adjust teaching ideas and innovate teaching methods of their own. The key to implement aesthetic education lies in the teachers.

\section{THE ADAPTATION OF AESTHETIC EDUCATION TO COLLEGE STUDENTS' PSYCHOLOGICAL MECHANISM}

With the advent of the information age, the art has been widely shown in the mass media such as television, computer, and network. It has become the indivisible part of modern people's daily life, spirit cultivation and learning [3]. The network era has brought the unprecedented impacts on education and the negative effects of network culture and network behavior on education cannot be ignored. Driven by commercial interests, the dissemination of the vulgar content by some media seriously affects the aesthetic ideal and tastes of people particularly young students, which makes them get stuck in "pleasure culture" and "fast food culture". Due to the great attraction of network culture, some people get addicted to net-surfing and TV watching. They are totally immersed in the virtual world emotionally and reject real-life interpersonal communication and social practice. Too much virtual life makes them fall into the virtual world and get lost. They even conduct some extreme behavior. Therefore, to prevent the violation of the minds of students by such undesirable phenomenon and trends, it is necessary to give full play to the aesthetic idea from multiple perspectives. We should teach students to make judgment with aesthetic theory, to identify the beneficial and available network resources, to make distinction between beauty and ugliness, civilization and barbarism, goodness and evil, noble sentiment and vulgar taste so as to help them have lofty ideals, cultivate noble sentiment and develop ethics [4].

What is the idea of aesthetic education in twenty-first century? We believe the idea of aesthetic education in twentyfirst century is revealed in the following aspects: it is human education in general sense; it is the aesthetic education integrated with education and teaching; it affects the whole process of people's education and growth process; it gives people artistic enjoyment and pleasure, which arouses students' interest in active experience, the desire and enthusiasm for active learning and stimulates their imagination and creativity thinking. This idea reflects the people-oriented concept, which establishes comprehensive, coordinated and sustainable development view so as to promote the all-round development of college students. However, at this stage the teaching of aesthetic education in class caters to the strong desire for knowledge and curiosity of network information of young students in time. So in the aesthetic education class, a qualified teacher of modern consciousness should actively create conditions, reasonably analyze psychological characteristics of students, utilize network information technology to arrange teaching contents scientifically and adjust the teaching ideas of their own to fit in with the needs of the times. Utilizing electrified education technology such as video and multimedia network in the aesthetic education and presenting information by means of text, image, audio, video and other diversified ways make aesthetic teaching more vivid and much easier to understand and remember. At the same time, timely transmission via internet enables teachers to master the new development of teaching and research so as to conduct teaching research and the exchange of experience better.

\section{ChangING TRADITIONAL TEACHING MODE AND FACILIT ATING THE OVERALL REFORM OF NETWORK AESTHETIC EDUCATION}

The method that traditional aesthetic education applies is single and relatively simple. In the school education, quite a few people take subject websites and network courseware as a new way and approach to instil in students the knowledge of the art. As everyone knows, there are many disadvantages of force-feeding teaching by teachers or via videos, so is network cramming. The problems that how to avoid such defects, give full play to the interactivity of network media and promote the overall reform of the aesthetic education become a real problem for aesthetic education research in network era.

In fact, aesthetic education is a kind of image education. It's not like knowledge education that must depend on the 
language and concepts interpretation to carry on, but it attracts and moves students via the vivid aesthetic images so that students would be strongly infected, experiencing and discovering beauty in aesthetic activities. They get inspired and enlightened, gradually forming their own aesthetic personality and ideal, which is aesthetic education in real sense. Therefore, aesthetic education should adopt a variety of ways and approaches to achieve. The single mode and path would only make the aesthetic education a kind of stiff and rigid indoctrination, which would turn the lively and vivid aesthetic education into a static, isolated and single knowledge imparting. Then it is not aesthetic education at all. If the beauty becomes something crammed, it would be sad for education.

Because of the timely transmission and rapid updating of network information resources, aesthetic education tends to take advantage of them to add relevant materials, which compensate for the limitations of textbooks to a large extent. At the same time driven by interest, students at this stage often propose the request to the teacher of increasing aesthetic information. Teachers tend to pay too much attention to the diversification of content and deviate from teaching focus. And the resulting disadvantages are that they have to glance over things hurriedly in face of a large amount of information and thus understand the teaching content superficially. The simple manipulation of modern media devices would take place of teachers and students as the center in class. Therefore, the inflexible teaching method of the application of information technology which simply caters to the taste of our students will interfere with the normal teaching effect. This requires teachers to pay more attention to the analysis and filtering of teaching content while cater to the students' psychological orientation. Teachers should fully understand the goals of teaching, try to achieve the perfect combination of teaching content and methods, construct a new doublesubject teaching mode which could play the leading role of teachers and fully reflect student's role of recognition entity as well. Based on this, We should cultivate students' innovation ability as well as information ability and try to achieve coordinated and scientific unity of teachers, students and modern teaching facilities. In addition, we should not ignore that students should be the main body of participation in teaching and that of the application of information technology apart from the use of network education. The interaction between teaching and learning stimulates the students' consciousness of participation. In order to make students experience the joy of learning in information technology education and actively build their own scientific framework of knowledge, we need to encourage them to enrich their own knowledge personally. Art teachers should take these factors into account and conduct teaching flexibly. For example, teachers could offer students the opportunities to participate and know about their amateur life. Teachers could lead more students to participate in the new educational mode as far as possible according to different situations. Due to various problems encountered in teaching practice of the new times, it will promote the school aesthetic education to analyze the pros and cons of teaching modes via applying network information resources in all aspects. We will continue to summarize teaching experience in practice.
IV. ADAPTING TO STUDENTS' PSYCHOLOGICAL MECHANISM DEVELOPMENT AND GIVING FULL PLAY TO THE ORIENTATION FUNCTIONS OF NETWORK AESTHETIC EDUCATION

Owing to the situation that the transmission of network information resources is timely and instant, aesthetic education tends to be deviate from the teaching focus in teaching content which is too multifarious, whereas the resulting disadvantages are that students have to glance over things hurriedly while receiving a large amount of information so that the understanding of teaching content is superficial. This requires teachers to pay more attention to the analysis and filtering of teaching content while cater to the students' psychological orientation. Teachers should fully understand the goals of teaching, try to achieve the perfect combination of teaching content and methods, construct a new double-subject teaching mode which could play the leading role of teachers and fully reflect student's role of recognition entity. We should cultivate students' innovation ability as well as information ability and try to achieve coordinated and scientific unity of teachers, students and modern teaching facilities. We should stimulate the students' consciousness of participation in the interaction between teaching and learning, encourage them to actively build their own scientific framework of knowledge and guide students to participate in the new educational mode as much as possible.

Strengthening aesthetic education is not only the original meaning of quality education, but also the requirements of building a harmonious society. The comprehensive development of man is the free man and the ideal life is aesthetic life. As Schiller said in the Aesthetic Letters that it is through beauty that people can achieve freedom. As one scholar says that one attains knowledge from learning and improves ability through practice, while one's quality is cultivated. Aesthetic education cannot be accomplished at one stroke. Therefore, we should make in-depth analysis of ideological situation and characteristics of psychological mechanism, conduct the study of the innovational education of aesthetic theory and practice and integrate it into the tutorial settings in view of the aesthetic education in Colleges and universities [5]. Colleges and universities should take the responsibility of the disseminator of aesthetic education. They should include the research of the aesthetic education theory in teaching and research, explore the law of aesthetic education in higher education as well as the effective ways of implementing the aesthetic education in the whole society, guide practice with scientific theory of aesthetic education. In the quality education of contemporary college students, colleges and universities should clarify the position of aesthetic education in the education policy and endeavor to cultivate builders and successors of the socialist cause who are developed all-round in morality, intelligence, physical capacity and aesthetics.

\section{REFERENCES}

[1] Yuan Shuya and Ma Changsheng. Aesthetic Education Coursebook[M].Kaifeng:Henan University Press, 1991. 
[2] Zhou Weiye. Network Aesthetic Education --- The Media Perspective of Art Education[M].Nanjing: Nanjing Press, 2009.

[3] Huangshan. The Approach Innovation of Art Education Applied in Technical Universities[J].Anhui Agricultural University Journal(Social Science Edition),2004.5.

[4] Ding Changfeng. The implementation Approaches of Aesthetic Education in College Students Administration [J].Chang'an University Journal(Social Science Edition),2007.1.

[5] Bi Enming and Lu Shuhong. Thoughts of Quality Education Implementation[J].Education Development Research.2008.18. 